Multidisciplinary Journal - Volume 3, Nomor 2, 2020

Contents list available at Multidisciplinary Journal website

Multidisciplinary Journal

Journal homepage: https://jurnal.unej.ac.id/index.php/multijournal

\title{
Hubungan Perilaku Penggunaan Alat Pelindung Diri (APD) dan Perilaku Personal Hygiene dengan Penyakit Kulit Menggunakan TRA (Theory of Reasoned Action)
}

\author{
The Correlation of Personal Protection Equipment Behaviour and Personal Hygiene Behaviour \\ toward Skin Disease by TRA (Theory of Reasoned Action) Approch \\ Icha Rohmah Damayanti Agustin ${ }^{1}$, Dewi Prihatini ${ }^{2}$, Isa Ma'rufi ${ }^{3}$ \\ ${ }^{1}$ Mahasiswa Pascasarjana Ilmu Kesehatan Masyarakat Universitas Jember ${ }^{2}$ Pascasarjana Universitas Jember \\ Email: ichaagustin165@yahoo.com
}

\begin{abstract}
ABSTRAK. Pemakaian alat pelindung diri (APD) dan perilaku personal hygiene adalah sebagai upaya untuk mencegah penyakit kulit pada pekerja. Penelitian ini bertujuan untuk menganalisis hubungan antara perilaku penggunaan Alat Pelindung Diri (APD), personal hygiene dengan penyakit kulit pada pemulung di TPA Pakusari Kabupaten Jember. Jenis penelitian adalah observasional analitik dendan desain cross sectional. Data yang digunakan adalah data primer yang diperoleh dari kuisioner 57 pemulung yang terdiri dari 36 perempuan dan 21 laki-laki. Alat analisis menggunakan analisis spss (cramer's V). Hasil pengujian instrumen menunjukkan bahwa semua variabel valid dan reliable sebagai alat pengumpul data. Hasil analisis data menunjukkan bahwa: 1) perilaku penggunaan Alat Pelindung Diri (APD) memiliki hubungan yang signifikan dengan penyakit kult. 2) perilaku personal hygiene memiliki hubungan yang signifikan dengan penyakit kulit.
\end{abstract}

Kata Kunci: penyakit kulit, perilaku penggunaan alat pelindung diri, perilaku personal hygiene.

ABSTRACT. In order to prevent skin disease among worker, both Personal Protective Equipment (PPE) usage and hygiene personal play important role. The objective of this study is to analyse the correlation between PPE usage and hygiene personal toward skin disease among scavenger in TPA Pakusari - Jember. This study was observational analytics, with cross sectional design. The number of participants was 57 scavengers, consist of 36 female and 21 males. The statistical analysis used Cramer's $\mathrm{V}$ by SPSS. The findings of this study is: 1) The PPE usage is correlated toward skin disease, 2) The hygiene personal is correlated toward skin disease.

Keyword: skin disease, PPE utilising, hygiene personal

\section{Pendahuluan}

Angka Prevalensi penyakit kulit dengan jenis dermatitis cukup tinggi di Jawa Timur yaitu sebesar 64,6\% (Riskesdas, 2007) ${ }^{[1]}$. Penyakit dermatitis kontak alergi menduduki urutan kesepuluh pada sepuluh besar penyakit terbanyak di Puskesmas Kabupaten Jember yaitu sebesar $32.640 \quad(2,39)$ (Profil Kesehatan Kabupaten Jember, 2014) ${ }^{[2]}$. Laporan penyakit kulit tahun 2018 dari Polindes Kertosari diperoleh pemulung yang menderita penyakit kulit sebanyak 7 orang dengan jenis penyakit bermacam-macam yaitu diantaranya dermatitis, penyakit akibat jamur, skabies, eksim.

Pemulung adalah orang yang setiap harinya memiliki pekerjaan mengambil sampah atau barang bekas tertentu kemudian di daur ulang. Kegiatan ini adalah salah satu jenis pekerjaan yang mempunyai risiko bahaya tinggi bagi kesehatan kulit maupun keselamatan kerja. Sampah dapat menjadi sumber berkumpulnya kuman dan tempat yang baik bagi berkembangnya vektor penyakit (Prasasti) [3].

Kulit adalah pembungkus elastis yang berfungsi melindungi tubuh terhadap pengaruh lingkungan dan cukup sensitif terhadap berbagai macam penyakit. (Purba, 2016) ${ }^{[4]}$ Perilaku personal hygiene adalah sebagai upaya untuk mencegah penyakit kulit. Bentuk perilaku personal hygiene misalnya dengan menjaga kebersihan kulit kepala dan rambut, kebersihan tangan,kuku dan kaki serta 
kebersihan pada kulit. Selain itu, perilaku penggunaan Alat Pelindung Diri (APD) juga perlu diperhatikan. Penggunaan Alat Pelindung Diri (APD) adalah salah satu usaha untuk menghindari paparan suatu risiko bahaya di tempat kerja (Tarwaka) $)^{[5]}$. Semakin lama dan sering seseorang kontak langsung dengan sampah dan jika tidak memperhatikan kesehatan perorangan dengan baik dan penggunaan alat pelindung diri tidak lengkap, memungkinkan beresiko terkena penyakit kulit. Jenisjenis Alat Pelindung Diri (APD) yang sangat erat kaitannya dengan sampah antara lain alat pelindung kepala, alat pelindung tangan, baju pelindung, alat pelindung kaki dan alat pelindung pernafasan (Anizar, 2012) [6]. Penjelasan mengenai masalah hubungan perilaku personal hygiene, perilaku dalam menggunakan Alat Pelindung Diri (APD) dengan kesehatan kulit membuat penelitian ini penting dibahas menggunakan TRA (Theory of Reasoned Action). Teori ini menghubungkan antara keyakinan, sikap, kehendak dan perilaku. (Priyoto, 2014) ${ }^{[7]}$

Berdasarkan latar belakang diatas, maka permasalahan yang dirumuskan ialah apa saja determinan penyakit kulit pada pemulung di TPA Pakusari dengan pendekatan TRA (Theory of Reasoned Action).

\section{Metode Penelitian}

Penelitian ini kuantitatif dengan jenis penelitan yang digunakn adalah survei analitik yang bertujuan untuk menganalisis hubungan personal hygiene dan perilaku penggunaan Alat Peindung Diri (APD) dengan penyakit kulit.

Lokasi penelitian ini di Tempat Pembuangan Akhir (TPA) Pakusari, Kabupaten Jember. Populasi dalam penelitian ini adalah pemulung dengan jumlah sampel sebanyak 57 responden.

Data primer penelitian didapatkan dari kuesioner wawancara kepada responden. Alat atau instrumen penelitian ini berupa kuesioner, lembar pemeriksaan Ujud Kelainan Kulit dan lembar observasi. Analisis yang digunakan adalah Cramer's $V$ menggunakan alat SPSS 22.0.

\section{Hasil dan Pembahasan}

a. Perilaku Personal Hygiene

Tabel 1. Perilaku Personal Hygiene Pemulung

\begin{tabular}{clcc}
\hline Variabel & Kategori & $\mathbf{N}$ & $\mathbf{\%}$ \\
\hline Personal Hygiene & Tidak baik & 53 & 93 \\
\cline { 2 - 4 } & Baik & 4 & 7 \\
\hline
\end{tabular}

Tabel 1 menjelaskan distribusi dari perilaku personal hygiene dimana kategori pengetahuan tidak baik sebanyak 93\% dan kategori baik $7 \%$.

b. Perilaku Penggunaan Alat Pelindung Diri (APD)

Tabel 2. Perilaku Pengguaan APD Pemulung

\begin{tabular}{lllc}
\hline \multicolumn{1}{c}{ Variabel } & Kategori & N & \% \\
\hline Perilaku & Tidak baik & 53 & 93 \\
\cline { 2 - 4 } Pengguaan APD & Baik & 4 & 7 \\
\hline
\end{tabular}

Tabel 2 menjelaskan distribusi dari perilaku personal hygiene dimana kategori pengetahuan tidak baik sebanyak 93\% dan kategori baik $7 \%$.

c. Distribusi Penyakit Pemulung

Tabel 3. Distribusi Pemeriksaan UKK pada Pemulung

\begin{tabular}{|c|c|c|}
\hline UKK & Jumlah (n) & Persentase $(\%)$ \\
\hline Hiperpigmentasi & 18 & 34,0 \\
\hline Dermatitis Kontak Iritan & 2 & 3,8 \\
\hline Eritema & 4 & 7,5 \\
\hline Scar & 4 & 7,5 \\
\hline $\begin{array}{ll}\text { Melanosit } & \text { dan } \\
\text { Hiperpigmentasi } & \end{array}$ & 4 & 7,5 \\
\hline Scar dan Hiperpigmentasi & 2 & 3,8 \\
\hline Erosi kulit & 1 & 1,9 \\
\hline $\begin{array}{l}\text { Hiperpigmentasi, Eritema } \\
\text { dan DKI }\end{array}$ & 1 & 1,9 \\
\hline Melanosit & 1 & 1,9 \\
\hline Dermatitis dan Urticaria & 1 & 1,9 \\
\hline Papule dan Hipopigmentasi & 1 & 1,9 \\
\hline Nevus / tahi lalat & 2 & 3,8 \\
\hline Hipopigmentasi & 1 & 1,9 \\
\hline Dermatitis & 4 & 7,5 \\
\hline Dermatitis Alergi & 2 & 3,8 \\
\hline Tinea corporis/Panu & 5 & 9,4 \\
\hline Total & 53 & 100,0 \\
\hline
\end{tabular}

Tabel 3 menunjukkan bahwa pemulung paling banyak menderita hiperpigmentasi kulit yaitu sebanyak 18 orang (34\%).

d. Sikap dalam Perilaku personal hygiene dan perilaku penggunaan APD

Tabel 4. Sikap

\begin{tabular}{clcc}
\hline Variabel & Kategori & N & \% \\
\hline Sikap & Negatif & 7 & 12,3 \\
\cline { 2 - 4 } & Positif & 50 & 87,7 \\
\hline
\end{tabular}

Tabel 4. Menjelaskan distribusi sikap pemulung dalam Perilaku personal hygiene dan perilaku penggunaan APD yaitu yang memiliki sikap positif 87,7\%.

e. Norma Subjektif dalam Perilaku personal hygiene dan perilaku penggunaan APD

Tabel 5. Norma Subjektif

\begin{tabular}{cllc}
\hline Variabel & Kategori & N & \% \\
\hline Norma subjektif & Lemah & 27 & 47,4 \\
\cline { 2 - 4 } & Kuat & 30 & 52,6 \\
\hline
\end{tabular}

Tabel 5. Menjelaskan distribusi norma subjektif pemulung dalam Perilaku personal hygiene dan perilaku penggunaan APD yaitu yang memiliki norma subjektif 
kuat $52,6 \%$.

f. Niat dalam Perilaku personal hygiene dan perilaku penggunaan APD

Tabel 6. Niat

\begin{tabular}{cllc}
\hline Variabel & Kategori & $\mathbf{N}$ & $\mathbf{\%}$ \\
\hline \multirow{2}{*}{ Niat } & Lemah & 30 & 52,6 \\
\cline { 2 - 4 } & Kuat & 27 & 47,4 \\
\hline
\end{tabular}

Tabel 6. Menjelaskan distribusi niat pemulung dalam Perilaku personal hygiene dan perilaku penggunaan APD yaitu yang memiliki niat lemah 52,6\%.

g. Hubungan Perilaku Penggunaan APD dengan Penyakit Kulit

Tabel. 7 Hubungan Perilaku Penggunaan APD dengan Penyakit Kulit

\begin{tabular}{|c|c|c|c|c|c|c|}
\hline \multirow[t]{3}{*}{ Penyakit } & \multicolumn{4}{|c|}{ Penggunaan APD } & \multicolumn{2}{|c|}{ Total } \\
\hline & \multicolumn{2}{|c|}{ Tidak Baik } & \multicolumn{2}{|c|}{ Baik } & \multirow[b]{2}{*}{$\begin{array}{c}\text { Juml } \\
\text { ah } \\
\text { (n) }\end{array}$} & \multirow[b]{2}{*}{$\begin{array}{l}\text { Persent } \\
\text { ase (\%) }\end{array}$} \\
\hline & $\begin{array}{l}\text { Jumla } \\
\text { h (n) }\end{array}$ & $\begin{array}{c}\text { Persenta } \\
\text { se }(\%)\end{array}$ & $\begin{array}{c}\text { Jumla } \\
\text { h (n) }\end{array}$ & $\begin{array}{c}\text { Persenta } \\
\text { se }(\%)\end{array}$ & & \\
\hline $\begin{array}{l}\text { Tidak } \\
\text { terdiagn } \\
\text { osa } \\
\text { mengala } \\
\text { mi } \\
\text { penyakit } \\
\text { kulit }\end{array}$ & 1 & 25 & 3 & 75 & 4 & 100 \\
\hline $\begin{array}{l}\text { Terdiagn } \\
\text { osa } \\
\text { mengala } \\
\text { mi } \\
\text { penyakit } \\
\text { kulit }\end{array}$ & 52 & 99 & 1 & 1 & 53 & 100 \\
\hline Total & 53 & & 4 & & 57 & \\
\hline Approx. $S$ & Cram & $s V 0,000$ & & & & \\
\hline
\end{tabular}

Tabel 7. Menunjukkan pemulung yang mengalami penyakit kulit sebanyak 53 pemulung dengan 52 pemulung memiliki perilaku penggunaan APD yang tidak baik dan hanya 1 pemulung saja yang memiliki perilaku penggunaan APD yang baik.

Hasil uji statistik Cramer's $V$ dengan menggunakan SPSS pada Tabel 7 didapatkan bahwa secara signifikan antara perilaku penggunaan Alat Pelidung Diri (APD) dengan penyakit kulit terdapat hubungan dengan nilai approx. sig Cramer's $V$ sebesar $0,000<0,05$.

h. Hubungan Perilaku Personal Hygiene dengan Penyakit Kulit

Tabel 8. Hubungan Perilaku Personal Hygiene dengan Penyakit Kulit

\begin{tabular}{lccccc}
\hline \multirow{2}{*}{ Penyakit } & \multicolumn{3}{c}{ Personal Hygiene } & \\
\cline { 2 - 5 } & $\begin{array}{c}\text { Tumlah } \\
\text { (n) }\end{array}$ & Persentase & Jumlah & Persentase & Jumlah \\
& $(\%)$ & (n) & $(\%)$ & (n) \\
\hline $\begin{array}{l}\text { Tidak } \\
\text { terdiagnosa }\end{array}$ & 1 & 25 & 3 & 75 & 4
\end{tabular}

\begin{tabular}{|c|c|c|c|c|c|c|}
\hline $\begin{array}{l}\text { mengalami } \\
\text { penyakit } \\
\text { kulit }\end{array}$ & & & & & & \\
\hline $\begin{array}{l}\text { Terdiagnosa } \\
\text { mengalami } \\
\text { penyakit } \\
\text { kulit }\end{array}$ & 52 & 99 & 1 & 1 & 53 & 100 \\
\hline Total & 53 & & 4 & & 57 & \\
\hline
\end{tabular}

Tabel 8. Menunjukkan Pemulung yang mengalami penyakit kulit sebanyak 53 pemulung dimana 52 pemulung memiliki personal hygiene yang tidak baik dan hanya 1 pemulung saja yang memiliki personal hygiene yang baik.

Berdasarkan hasil uji statistik Cramer's $V$ dengan menggunakan SPSS pada Tabel 8 didapatkan bahwa terdapat hubungan yang signifikan antara perilaku penggunaan personal hygiene dengan penyakit kulit dengan nilai approx. sig Cramer's $V$ sebesar $0,000<0,05$.

Perilaku penggunaan APD merupakan tindakan ataupun cara memakai, mengenakan alat pelindung dengan tujuan untuk melindungi diri terhadap segala macam bahaya yang mungkin terjadi kapan saja tanpa diduga. Berdasarkan uji penelitian menggunakan uji statistik asosiasi Cramer Coefficient $C$ didapatkan hubungan yang signifikan antara perilaku penggunaan APD dengan penyakit kulit pada pemulung di TPA Pakusari Kabupaten Jember dengan nilai approx. sig Cramer's $V$ sebesar $0,00<0,05$. Hal ini dapat terjadi karena penggunaan APD sangatlah penting, ditinjau berdasarkan tujuannya penggunaan APD yaitu guna melindungi diri dari bahaya pekerjaan yang berakibat pada Penyakit Akibat Kerja (PAK) atau Kecelakaan Akibat Kerja (KAK), maka dari itu penggunaan APD memiliki peranan yang sangat penting, karena hal ini penting bukan saja untuk tenaga kerja tetapi juga untuk perusahaan/instansi (Fath, 2015) ${ }^{[8]}$

Personal hygiene atau kebersihan pada diri seseorang sangat berengaruh terhadap aktivitas atau perilaku sosial seseorang. Saat masa kecil, kebiasaan keluarga memengaruhi perilaku hygiene, salah satu contohnya pada saat mandi. Saat remaja, teman sebaya dapat mempengaruhi perilaku hygiene seseorang. Saat dewasa, harapan tentang penampilan pribadi dipengaruhi oleh teman dan kelompok kerja. Kemudian pada lansia, beberapa perubahan akan terjadi dalam praktik hygiene seiring dengan perubahan pada kondisi fisiknya. Berdasarkan pada hasil penelitian menggunakan uji statistik asosiasi Cramer Coefficient $C$ didapatkan hubungan yang signifikan antara perilaku Personal Hygiene dengan dermatitis kontak iritan pada pemulung di TPA Pakusari Kabupaten Jember Tatähgan nilai approx. sig Cramer's $V$ sebesar $0,00<0,05$. Hasil Paera penelitian ini sejalan dengan penelitian yang dilakukan oleh ZZebua, dkk (2014) [9] yaitu adanya hubungan yang bermakna antara pengetahuan tentang personal hygiene dengan keluhan kulit $(\mathrm{p}=0,022)$.

\section{Kesimpulan}

CMultidisciplinaryJournal-ISSN:2716-2419,Allrightsreserved 
Berdasarkan penelitian yang telah dilakukan diperoleh beberapa kesimpulan sebagai berikut:

1. Penyakit kulit yang paling banyak diderita oleh pemulung adalah hiperpigmentasi, tinea corporis, eritema, scar, melanosit disertai hiperpigmentasi dan dermatitis

2. Perilaku personal hygiene (kebersihan kulit kepala , rambut, kebersihan kuku, tangan dan kaki, kebersihan kulit) pemulung di TPA Pakusari sebagian besar tidak baik.

3. Perilaku penggunaan Alat Pelindung Diri (APD) meliputi (sepatu, topi atau tudung kepala, sarung tangan karet, pakaian / baju lengan panjang dan celana panjang) pemulung di TPA Pakusari sebagian besar tidak baik

4. Sikap dalam Perilaku Personal Hygiene dan Perilaku Penggunaan Alat Pelindung Diri (APD) pada Pemulung di TPA Pakusari Jember sebagian besar positif.

5. Norma subjektif dalam Perilaku Personal Hygiene dan Perilaku Penggunaan Alat Pelindung Diri (APD) pada Pemulung di TPA Pakusari Jember sebagian besar kuat.

6. Niat dalam Perilaku Personal Hygiene dan Perilaku Penggunaan Alat Pelindung Diri (APD) pada Pemulung di TPA Pakusari Jember sebagian besar kuat.

7. Terdapat hubungan yang signifikan antara perilaku personal hygiene dengan penyakit kulit pada pemulung di TPA Pakusari.

8. Terdapat hubungan yang signifikan antara perilaku penggunaan APD dengan penyakit kulit pada pemulung di TPA Pakusari.

\section{Ucapan Terima Kasih}

Terima kasih kepada Dinas Lingkungan Hidup Kab Jember dan TPA Pakusari Kab Jember yang telah berkenan memberikan ijin atas pelaksanaan penelitian ini.

\section{Referensi}

[1] Riset Kesehatan Dasar. 2007. Badan Penelitian dan Pengembangan Kesehatan. Departemen Kesehatan. Republik Indonesia.

[2] Dinas Kesehatan Jember. 2014. Profil Kesehatan Kabupaten Jember: Dinas Kesehatan.

[3] Prasasti, C. 2017. Gangguan Kulit Pemulug di TPA Kenep Ditinjau Dari Aspek Keselamatan dan Kesehatan Kerja. The Indonesian Journal of Occupational Safety and Health, Volume 6, No. 02, MeiAgustus 2017: 135-145.

[4] Purba, D. 2016. Hubungan Personal Hygiene, Penggunaan Alat Pelindung Diri dan Karakteristik Pekerja Petugas Pengangkut Sampah dengan Keluhan Gangguan Kulit di Kelurahan Petisah Tengah Tahun 2016. Skripsi Universitas Sumatera Utara.

[5] Tarwaka. 2008. Kesehatan dan Keselamatan Kerja Manajemen dan Implementasi K3 di Tempat Kerja. Surakarta: HARAPAN PRESS.

[6] Anizar. 2010. Teknik Keselamatan dan Kesehatan Kerja di Industri.
Yogyakarta: Graha Ilmu.

[7] Priyoto. 2014. Teori Sikap dan Perilaku dalam Kesehatan. Yogyakarta: Nuha Medika.

Fath, R. 2015. Pengaruh Lingkungan Kerja Non Fisik dan Karakteristik Pekerjaan terhadap Kepuasan Kerja. Skripsi Universitas Negeri Yogyakarta.

[9] Zebua. 2014. Hubungan Personal Hygiene dengan Keluhan Kulit pada Pemulung dan Fasilitas Sanitasi di TPA Terjun Kelurahan Terjun Kecamatan Medan Marelan Tahun 2014. Jurnal Lingkungan dan Kesehatan Kerja, Volume 3, No. 02, 2014 